\title{
Perfil bacteriano das superfícies e equipamentos da Unidade de Terapia Intensiva de um Hospital Universitário
}

\author{
Bacterial profile of surfaces and equipment in the Intensive Care Unit of a University Hospital \\ Perfil bacteriano de superficies y equipos en la Unidad de Cuidados Intensivos de un Hospital \\ Universitario
}

Recebido: 17/07/2021 | Revisado: 22/07/2021 | Aceito: 23/07/2021 | Publicado: 31/07/2021

\author{
Marisa Catarina Mesquita Espíndola \\ ORCID: https://orcid.org/0000-0003-3379-4057 \\ Universidade de Pernambuco, Brasil \\ E-mail: marisacmespindola@gmail.com \\ Cleusa Wanderley de Queiroz Andrade \\ ORCID: https://orcid.org/0000-0001-6113-1432 \\ Universidade Federal do Vale do São Francisco, Brasil \\ E-mail: cleusawqandrade@gmail.com \\ Katia Suely Batista Silva \\ ORCID: https://orcid.org/0000-0001-6146-4229 \\ Universidade Federal do Vale do São Francisco, Brasil \\ E-mail: katiasuelybs@gmail.com \\ Mirthes Maria Rodrigues Santana \\ ORCID: https://orcid.org/0000-0002-7087-7145 \\ Universidade Federal do Vale do São Francisco, Brasil \\ E-mail: Mirthes-mari@hotmail.com \\ Rafael Medeiros Gomes \\ ORCID: https://orcid.org/0000-0002-7290-299X \\ Universidade Federal do Vale do São Francisco, Brasil \\ E-mail: rafaebserh@gmail.com \\ Kátia Regina de Oliveira \\ ORCID: https://orcid.org/0000-0002-3049-0827 \\ Universidade Federal do Vale do São Francisco, Brasil \\ E-mail: katia.regina@ebserh.gov.br \\ Marcos Duarte Guimarães \\ ORCID: https://orcid.org/0000-0002-9458-5649 \\ Universidade Federal do Vale do São Francisco, Brasil \\ E-mail: marcosduarte500@gmail.com \\ Carine Rosa Naue \\ ORCID: https://orcid.org/0000-0003-4215-3606 \\ Universidade Federal do Vale do São Francisco, Brasil \\ E-mail: crnaue@yahoo.com.br
}

\begin{abstract}
Resumo
Existem evidências que superfícies e objetos agem como reservatórios, facilitando, assim, infecções cruzadas. O objetivo do presente trabalho foi avaliar o perfil bacteriano em superfícies e equipamentos da UTI de um Hospital Universitário no sertão do Vale do São Francisco. Trata-se de um estudo transversal e descritivo. O trabalho foi realizado na UTI, onde foram amostrados as seguintes superfícies e equipamentos: ventilador mecânico; botões de comando do monitor cardíaco; diafragma do estetoscópio; mesa de cabeceira; dispensador de soro/alimento; cortinas ao redor do leito; parede ao redor do leito e bomba de infusão contínua. As amostras foram coletadas, utilizando-se swabs embebidos em solução salina. Após a passagem, eles foram armazenados em tubo e transportados para o Laboratório onde foram realizadas as análises microbiológicas. O total de bactérias encontradas, independente dos leitos, equipamentos e superfícies amostradas foi de 134, destas, 20 (15\%) são consideradas possíveis bactérias causadoras de infecções hospitalares. No que se refere ao perfil de resistência das bactérias aos principais antibióticos, os Staphylococcus aureus, foram 100\% resistentes à oxacilina e os isolados de Enterococcus sp. apresentaram $20 \%$ de resistência intermediária à vancomicina e $20 \%$ de resistência à ampicilina. Foi observado que todos os isolados de Klebsiella pneumoniae foram resistentes à ampicilina + sulbactam e 100\% sensíveis ao restante dos antibióticos testados. Para Acinetobacter baumannii foi observado $43 \%$ de resistência intermediária à ceftriaxona e $57 \%$ de resistência ao meropenem. O presente estudo mostra que nas superfícies e equipamentos da UTI estão presentes bactérias multirresistentes que podem causar infecções hospitalares.
\end{abstract}

Palavras-chave: Controle de infecções; Unidade de Terapia Intensiva; Contaminação de equipamentos. 


\begin{abstract}
There is evidence that surfaces and objects act as reservoirs, thus facilitating cross-infections. The objective of the present work was to evaluate the bacterial profile on surfaces and equipment of the ICU of the University Hospital of the Federal University of Vale do São Francisco. This is a cross-sectional and descriptive study. The study was carried out in the ICU, where the following surfaces and equipment were sampled: mechanical ventilator; cardiac monitor command buttons; stethoscope diaphragm; bedside table; serum/food dispenser; curtains around the bed; wall around the bed and continuous infusion pump. Samples were collected using swabs soaked in saline solution. After passage, they were stored in a tube and transported to the Laboratory where microbiological analyzes were performed. The total bacteria found, regardless of the beds, equipment and surfaces sampled was 134, of these, 20 (15\%) are considered possible bacteria that cause hospital infections. Regarding the resistance profile of bacteria to the main antibiotics, Staphylococcus aureus were $100 \%$ oxacillin resistant and Enterococcus sp. presented $20 \%$ intermediate resistance to vancomycin and $20 \%$ resistance to ampicillin. All isolates of Klebsiella pneumoniae were found to be ampicillin + sulbactam resistant and $100 \%$ sensitive to the remaining antibiotics tested. Acinetobacter baumannii showed $43 \%$ intermediate resistance to ceftriaxone and $57 \%$ meropenem resistance. The present study shows that on the ICU surfaces and equipment there are multiresistant bacteria that can cause nosocomial infections.
\end{abstract}

Keywords: Infection control; Intensive Care Units; Equipment contamination.

\title{
Resumen
}

Existe evidencia de que las superficies y los objetos actúan como reservorios, lo que facilita las infecciones cruzadas. El objetivo del presente trabajo fue evaluar el perfil bacteriano en las superficies y equipos de la UCI de um Hospital Universitario del Vale do São Francisco. Este es unestudio transversal y descriptivo que se realizóenla UCI, donde se tomaron muestras de las siguientes superficies y equipos: ventilador mecánico; botones de comando del monitor cardíaco; diafragma de estetoscopio; mesilla de noche; dispensador de suero / comida; cortinas alrededor de la cama; paredalrededor de la cama y bomba de infusión continua. Las muestras se recogieronconhisopos empapados ensolución salina. Después del paso, se almacenaron em un tubo y se transportaron al Laboratorio donde se realizaron análisis microbiológicos. El total de bacterias encontradas, independientemente de las camas, equipos y superficiesmuestreadasfue de 134, de estos, 20 (15\%) se consideran posibles bacterias que causan infecciones hospitalarias. Encuanto al perfil de resistencia de las bacterias a los antibióticos principales, Staphylococcus aureus era $100 \%$ resistente a laoxacilina y Enterococcus sp. presentó $20 \%$ de resistencia intermedia a la vancomicina y $20 \%$ de resistencia a la ampicilina. Se encontró que todos losaislamientos de Klebsiella pneumoniae eran resistentes a ampicilina + sulbactam y $100 \%$ sensibles a los antibióticos restantes probados. Acinetobacter baumannii mostró $43 \%$ de resistencia intermedia a ceftriaxona y $57 \%$ de resistencia a meropenem. El presente estudiomuestra que enlassuperficies y equipos de la UCI hay bacterias multirresistentes que pueden causar infecciones nosocomiales.

Palabras clave: Control de infecciones; Unidades de Cuidados Intensivos; Contaminación de equipos.

\section{Introdução}

As Infecções Hospitalares (IH) constituem um grave problema de saúde pública e causam impactos importantes na morbidade, mortalidade e custeio dos serviços hospitalares. IH é definida como qualquer infecção adquirida após a internação de um paciente em um hospital e que também pode se manifestar durante e após a alta, desde que estejam relacionados com procedimentos relacionados durante a internação. Os casos de IH aumentam ainda mais quando o paciente necessita de cuidados que exigem uma monitoração contínua e intervenções mais invasivas (Brixner et al., 2016; Portaria $n^{\circ}$ 2616, 1998).

Apesar de não ser possível dizer com precisão que superfícies e objetos contaminados podem causar infecções, indubitavelmente existem evidências que essas fontes agem como reservatórios, facilitando, assim, infecções cruzadas (Ferreira et al., 2011; Boyce, 2007).

Diversos fatores podem influenciar a contaminação de superfícies, dentre eles estão as taxas de transmissão cruzada, as condições do paciente, a estrutura da unidade e a intensidade dos cuidados. Os pacientes internados nas Unidades de Terapia Intensiva (UTI) encontram-se graves e necessitam de monitoramento e suporte contínuos, além de apresentarem enfermidades ou condições clínicas susceptíveis à infecção. Os equipamentos e superfícies dos leitos de uma UTI, são constantemente tocados e utilizados por profissionais de saúde o que faz com que aumente os índices de contaminação hospitalar, pois esses se comportam como importantes reservatórios de bactérias, principalmente as multirresistentes, o que dificulta o tratamento das infecções relacionadas à assistência à saúde (Ferreira et al., 2011; Ferreira et al., 2013; Sales et al., 2014). E, como constatado, 
a contaminação de superfícies em unidades de cuidado intensivo tem sido identificada em surtos e transmissão cruzada de patógenos entre pacientes críticos (Russoto et al., 2015).

Sabe-se que a microbiota endógena dos pacientes é também uma fonte real de contaminação, que pode ser transmitida através dos profissionais, principalmente quando não ocorre uma correta higienização das mãos. Além disso, o ambiente ao redor dos pacientes e equipamentos utilizados na prestação de cuidados também pode conter microrganismos que podem ser transmitidos para os pacientes, profissionais e outros objetos e equipamentos (Ferreira et al., 2011; Boyce, 2007).

Há uma correlação entre a presença de patógenos resistentes em superfícies inanimadas em um ambiente hospitalar e a frequência com que são limpos, a técnica utilizada na limpeza e o uso correto de desinfetantes. Apesar das principais causas de infecção hospitalar estarem relacionadas ao doente predisposto à infecção e com os procedimentos diagnósticos e terapêuticos utilizados, o espaço estrutural das UTI's, assim como os critérios de limpeza e desinfecção do ambiente constituem fatores preponderantes quando se considera a possibilidade de influência ambiental na disseminação e transmissão de patógenos. Com isso, o rigor desses procedimentos também deve ser considerado com o intuito de reduzir a incidência de colonização ou infecção nos pacientes (Ferreira et al., 2013; Sales et al., 2014; Moraes et al., 2013; Andrade et al., 2000).

Diante da importância do ambiente como reservatório e como possível fonte de transmissão de microrganismos que causam IH em UTI's, o objetivo deste trabalho foi avaliar o perfil bacteriano em superfícies e equipamentos da UTI do HUUNIVASF (EBSERH).

\section{Metodologia}

O experimento foi realizado na UTI de um Hospital Universitário do Sertão do Vale do São Francisco. Trata-se de um estudo transversal e descritivo desenvolvido com o intuito de determinar o papel das superfícies e equipamentos como reservatório de agentes etiológicos bacterianos associados às $\mathrm{IH}$.

Na UTI, foram analisados os seguintes superfícies e equipamentos: ventilador mecânico; botões de comando do monitor cardíaco; diafragma do estetoscópio; mesa de cabeceira; dispensador de soro/alimento; cortinas ao redor do leito; parede ao redor do leito e bomba de infusão contínua.

As amostras das superfícies e dos equipamentos foram coletadas, utilizando-se um molde de papel filtro de área de 1 $\mathrm{cm}^{2}$ e swabs embebidos em solução salina. Após a passagem do $s w a b$, nas superfícies e equipamentos, eles foram armazenados em tubo contendo 5mL meio líquido BHI (Brain Heart Infusion). Em seguida, as amostras foram transportadas para o Laboratório de Análises Clínicas/Setor Microbiologia do Hospital, onde foram realizadas as análises microbiológicas. Cada superfície e equipamento foram amostrados em 4 pontos diferentes.

No laboratório, os caldos BHI foram incubados a $37^{\circ} \mathrm{C}$ por 48 horas. Para o isolamento das bactérias, as amostras foram semeadas em Ágar Sangue (AS) e incubadas a $37^{\circ} \mathrm{C}$ por 24 horas. Após o período de incubação foi realizado a coloração de Gram e as provas bioquímicas para a identificação de cada espécie. Para identificação dos cocos Gram positivos foi realizada a prova de catalase. Quando a catalase foi positiva, foi realizado a prova de coagulase, e quando a catalase foi negativa, utilizou-se o Kit para Enterococcus, bacitracina e optoquina para identificar as espécies. Para a identificação de bacilos Gram negativos foram utilizados os kits para identificação de Enterobactérias e/ou de Não Fermentadores de glicose PROBAC®, conforme as instruções do fabricante.

As bactérias identificadas foram submetidas ao antibiograma pelo método de Ágar Difusão em Disco conforme as instruções CLSI (2018) e a escolha dos antimicrobianos realizada conforme o microrganismo isolado. Os resultados foram armazenados e analisados em uma planilha eletrônica de dados (Microsoft Excel® 2003). 


\section{Resultados}

O total de bactérias encontradas, independente dos leitos, equipamentos e superfícies amostradas foi de 134, destas, 20 (15\%) são consideradas possíveis bactérias causadoras de IH. O restante das bactérias isoladas (89 isolados) encontra-se no grupo dos Staphylococcus coagulase negativa, que na sua grande maioria colonizam a pele; mas, dependendo da situação de vulnerabilidade em que se encontra o paciente, pode tornar-se um patógeno; e as bactérias do ambiente (25 isolados), assim chamadas no presente estudo, pois não foram identificadas pelas provas bioquímicas utilizadas na rotina de identificação de bactérias de interesse clínico e possuíam morfologia de bactérias presentes no ambiente.

Dentre as bactérias possivelmente causadoras de IH identificadas nos equipamentos e superfícies da UTI, a ocorrência maior foi de Acinetobacter baumannii e Staphylococcus aureus com um total de sete isolados de cada, seguido de Enterococcus sp. com cinco isolados e Klebsiella pneumoniae com um isolado encontrado (Figura 1).

Figura 1. Ocorrência de bactérias em superfícies e equipamentos da UTI da UTI do HU/UNIVASF (EBSERH).

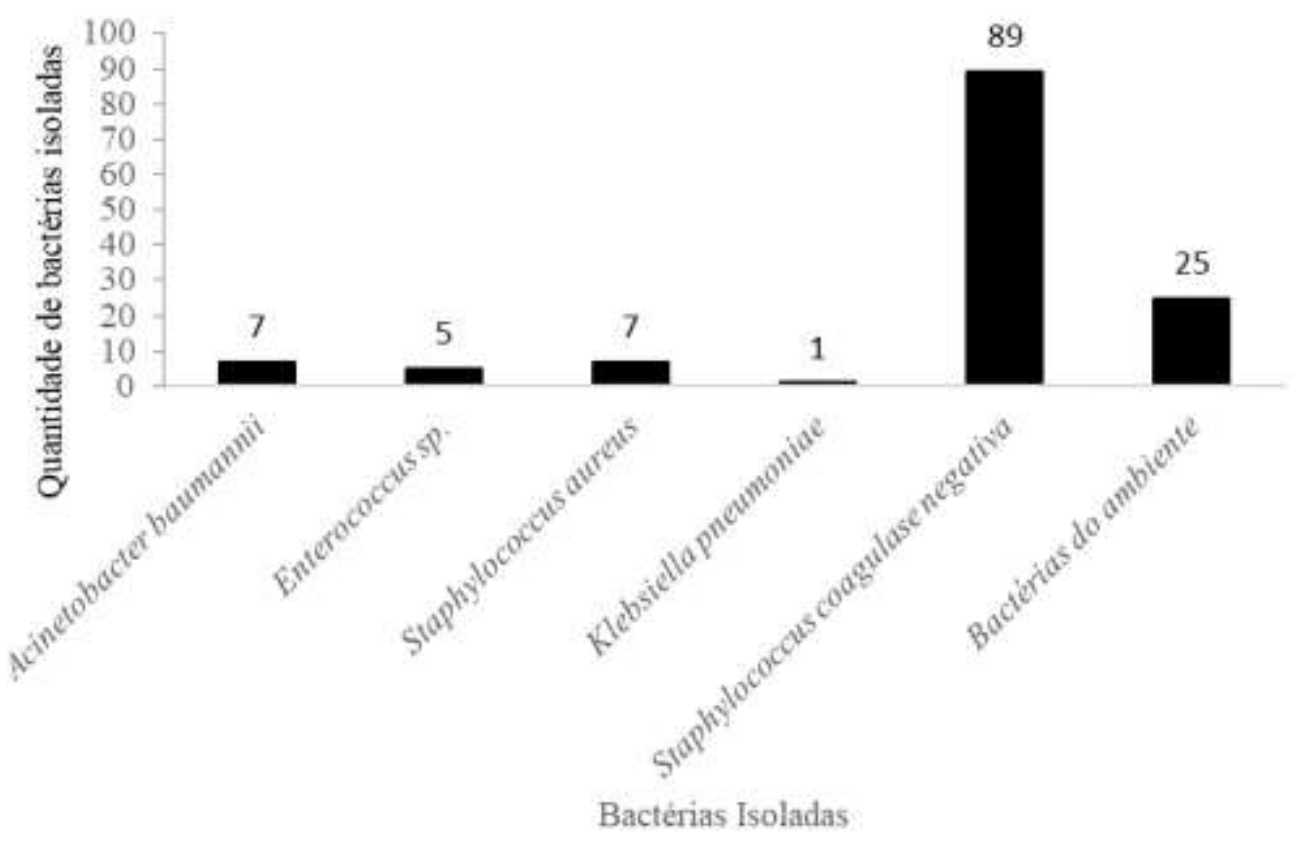

Fonte: Autores (2021).

Observa-se na Tabela 1 que em todos os leitos analisados foram isoladas possíveis bactérias causadoras de IH. Dos seis dispensadores de soro analisados, dois (leito 2 e 5) apresentaram-se contaminados com Staphylococcus aureus, assim como o ventilador mecânico do leito 01 e os botões do monitor cardíaco do leito 02 estavam contaminados por este microrganismo. Nas mesas de cabeceira foram isolados Enterococcus sp. E Staphylococcus aureus, leito 01 e 02 respectivamente. No leito 04 , tanto no diafragma do estetoscópio, quanto no ventilador mecânico foram identificados isolados de Acinetobacter baumannii.

Quanto às bombas de infusão, foram identificados isolados de Enterococcus sp. e Acinetobacter baumannii no leito 01 e 02 , respectivamente e na cortina ao redor do leito 02 foram encontrados Enterococcus sp., Staphylococcus aureus e Acinetobacter baumannii. Não houve crescimento bacteriano na parede ao redor do leito e na cortina do leito 01 e na parede ao redor do leito 06.

O local onde mais foi identificado contaminação por bactérias causadoras de IH foi no diafragma do estetoscópio, onde foram identificadas Enterococcus sp., Klebsiella pneumoniae, Acinetobacter baumannii e Staphylococcus aureus. 
Importante ressaltar que o estetoscópio é um dos equipamentos mais manipulados no leito de pacientes críticos, devido ao exame físico por parte dos profissionais que assistem o doente.

Tabela 1. Ocorrência de bactérias em superfícies e equipamentos, por leitos analisados, da UTI do HU/UNIVASF (EBSERH).

\begin{tabular}{|c|c|c|}
\hline & Equipamentos e superfícies & Bactérias isoladas \\
\hline LEITO 1 & $\begin{array}{l}\text { Dispensador de soro/alimento } \\
\text { Bomba de infusão contínua }\end{array}$ & $\begin{array}{l}\text { Bactéria do ambiente } \\
\text { Enterococcus sp. }\end{array}$ \\
\hline & $\begin{array}{l}\text { Parede ao redor do leito } \\
\text { Mesa de cabeceira } \\
\text { Botões do monitor cardíaco } \\
\text { Diafragma do estetoscópio } \\
\text { Ventilador mecânico } \\
\text { Cortina ao redor do leito } \\
\end{array}$ & $\begin{array}{l}\text { Não houve crescimento bacteriano } \\
\text { Enterococcus } \mathrm{sp} \text {. } \\
\text { S. coagulase negativa } \\
\text { Enterococcu ssp. } \\
\text { S. aureus } \\
\text { Não houve crescimento bacteriano }\end{array}$ \\
\hline LEITO 2 & $\begin{array}{l}\text { Dispensador de soro/alimento } \\
\text { Bomba de infusão contínua } \\
\text { Parede ao redor do leito } \\
\text { Mesa de cabeceira } \\
\text { Botões do monitor cardíaco } \\
\text { Diafragma do estetoscópio } \\
\text { Ventilador mecânico } \\
\text { Cortina ao redor do leito } \\
\end{array}$ & $\begin{array}{l}\text { S. aureus } \\
\text { Acinetobacter baumannii } \\
\text { S. coagulase negativa } \\
\text { S. aureus } \\
\text { S. aureus } \\
\text { S. coagulase negativa e bactéria do ambiente } \\
\text { S. coagulase negativa } \\
\text { Enterococcussp., S. aureus, Acinetobacter baumannii }\end{array}$ \\
\hline LEITO 3 & $\begin{array}{l}\text { Dispensador de soro/alimento } \\
\text { Bomba de infusão contínua } \\
\text { Parede ao redor do leito } \\
\text { Mesa de cabeceira } \\
\text { Botões do monitor cardíaco } \\
\text { Diafragma do estetoscópio } \\
\text { Ventilador mecânico } \\
\text { Cortina ao redor do leito }\end{array}$ & $\begin{array}{l}\text { Bactéria do ambiente } \\
\text { Bactéria do ambiente } \\
S \text {. coagulase negativa e bactéria do ambiente } \\
\text { S. coagulase negativa } \\
\text { S. coagulase negativa } \\
\text { Klebsiella pneumoniae e Acinetobacter baumannii } \\
\text { S. coagulase negativa e bactéria do ambiente } \\
\text { S. coagulase negativa }\end{array}$ \\
\hline LEITO 4 & $\begin{array}{l}\text { Dispensador de soro/alimento } \\
\text { Bomba de infusão contínua } \\
\text { Parede ao redor do leito } \\
\text { Mesa de cabeceira } \\
\text { Botões do monitor cardíaco } \\
\text { Diafragma do estetoscópio } \\
\text { Ventilador mecânico } \\
\text { Cortina ao redor do leito }\end{array}$ & $\begin{array}{l}\text { S. coagulase negativa } \\
\text { S. coagulase negativa } \\
\text { Bactéria do ambiente } \\
\text { S. coagulase negativa } \\
\text { S. coagulase negativa } \\
\text { Acinetobacter baumannii } \\
\text { Acinetobacter baumannii } \\
\text { S. coagulase negativa e bactéria do ambiente }\end{array}$ \\
\hline LEITO 5 & $\begin{array}{l}\text { Dispensador de soro/alimento } \\
\text { Bomba de infusão contínua } \\
\text { Parede ao redor do leito } \\
\text { Mesa de cabeceira } \\
\text { Botões do monitor cardíaco } \\
\text { Diafragma do estetoscópio } \\
\text { Ventilador mecânico } \\
\text { Cortina ao redor do leito }\end{array}$ & $\begin{array}{l}\text { S. aureus } \\
\text { S. coagulase negativa e bactéria do ambiente } \\
\text { S. coagulase negativa } \\
\text { S. coagulase negativa } \\
\text { S. coagulase negativa e bactéria do ambiente } \\
\text { Acinetobacter baumannii e } S \text {. aureus } \\
\text { S. coagulase negativa } \\
\text { S. coagulase negativa }\end{array}$ \\
\hline LEITO 6 & $\begin{array}{l}\text { Dispensador de soro/alimento } \\
\text { Bomba de infusão contínua } \\
\text { Parede ao redor do leito } \\
\text { Mesa de cabeceira } \\
\text { Botões do monitor cardíaco } \\
\text { Diafragma do estetoscópio } \\
\text { Ventilador mecânico } \\
\text { Cortina ao redor do leito }\end{array}$ & $\begin{array}{l}\text { Bactéria do ambiente } \\
S \text {. coagulase negativa } \\
\text { Não houve crescimento bacteriano } \\
\text { S. coagulase negativa } \\
S \text {. coagulase negativa e bactéria do ambiente } \\
\text { S. coagulase negativa } \\
S \text {. coagulase negativa } \\
S \text {. coagulase negativa }\end{array}$ \\
\hline
\end{tabular}


Tabela 2. Perfil de resistência e sensibilidade das bactérias isoladas em superfícies e equipamentos da UTI do HU/UNIVASF (EBSERH).

\begin{tabular}{|c|c|c|c|c|c|c|c|c|}
\hline \multirow{2}{*}{$\begin{array}{c}\text { ANTIBIÓTICOS } \\
\text { TESTADOS }\end{array}$} & \multicolumn{2}{|c|}{ S. aureus ${ }^{I}$} & \multicolumn{2}{|c|}{ Enterococcussp } & \multicolumn{2}{|c|}{ K. pneumoniae ${ }^{2}$} & \multicolumn{2}{|c|}{ A. baumannii ${ }^{3}$} \\
\hline & $\mathbf{R}^{4}$ & $\mathbf{S}^{5}$ & $\mathbf{R}$ & $\bar{S}$ & $\mathbf{R}$ & $\mathbf{S}$ & $\mathbf{R}$ & $\bar{S}$ \\
\hline CLINDAMICINA & 100 & 0 & NT & NT & NT & NT & NT & NT \\
\hline TETRACICLINA & 100 & 0 & NT & NT & 0 & 100 & 57 & 43 \\
\hline VANCOMICINA & NT & NT & 0 & 80 & NT & NT & NT & NT \\
\hline CEFEPIME & NT & NT & NT & NT & 0 & 100 & 57 & 43 \\
\hline $\mathrm{AMP}+\mathrm{SUB}^{6}$ & NT & NT & NT & NT & 100 & 0 & 57 & 43 \\
\hline $\mathrm{CIPRO}^{7}$ & NT & NT & NT & NT & 0 & 100 & 57 & 43 \\
\hline GENTAMICINA & 86 & 14 & NT & NT & 0 & 100 & 57 & 43 \\
\hline CEFTRIAXONA & NT & NT & NT & NT & 0 & 100 & 57 & 0 \\
\hline AMPICILINA & NT & NT & 20 & 80 & 0 & 100 & NT & NT \\
\hline CEFOXITINA & NT & NT & NT & NT & 0 & 100 & NT & NT \\
\hline OXACILINA & 100 & 0 & NT & NT & NT & NT & NT & NT \\
\hline CLORANFENICOL & 100 & 0 & NT & NT & NT & NT & NT & NT \\
\hline LEVOFLOXACINA & 100 & 0 & NT & NT & NT & NT & NT & NT \\
\hline PENICILINA & 100 & 0 & NT & NT & NT & NT & NT & NT \\
\hline PIPER+TAZO ${ }^{8}$ & NT & NT & NT & NT & 0 & 100 & 57 & 43 \\
\hline COLISTINA & NT & NT & NT & NT & 0 & 100 & NT & NT \\
\hline MEROPENEM & NT & NT & NT & NT & 0 & 100 & 57 & 43 \\
\hline AMICACINA & NT & NT & NT & NT & 0 & 100 & 57 & 43 \\
\hline
\end{tabular}

Legenda: ${ }^{1}$ : Staphylococcus aureus; ${ }^{2}:$ Klebsiella pneumoniae ${ }^{3}:$ Acinetobacter baumannii; ${ }^{4}$ : Resistente; ${ }^{5}$ : Sensível; ${ }^{6}$ : ampicilina e sulbactam; ${ }^{7}$ : Ciprofloxacino; ${ }^{8}$ : piperacilina sódica + tazobactam; NT: não testado. Fonte: Autores (2021).

No que se refere ao perfil de resistência e sensibilidade das bactérias identificadas, para os isolados de Staphylococcus aureus, $86 \%$ foram resistentes a gentamicina e 100\% resistentes a clindamicina, oxacilina, tetraciclina, cloranfenicol, levofloxacina e penicilina. Os isolados de Enterococcu ssp. apresentaram $20 \%$ de resistência intermediária à vancomicina e $20 \%$ de resistência a ampicilina. Para Klebsiella pneumoniae todos os isolados foram resistentes a ampicilina + sulbactam e $100 \%$ sensíveis a tetraciclina, cefepime, ciprofloxacino, gentamicina, ceftriaxona, ampicilina, cefoxitina, piperacilina e tazobactam, colistina, meropenem e amicacina. Para Acinetobacter baumannii foi observado 43\% de resistência intermediária a ceftriaxona e $57 \%$ de resistência a tetraciclina, cefepime, ampicilina + sulbactam, ciprofloxacino, gentamicina, ceftriaxona, piperacilina + tazobactam, meropenem e amicacina. 


\section{Discussão}

Em uma UTI os índices de IH são altos, a presença de microrganismos em superfícies e equipamentos inanimados, como estetoscópios, prontuários, dentre outros, podem ter papel significativo nas infecções cruzadas (Russoto et al., 2015). Em relação ao estetoscópio, estudo realizado em Lima, Peru, demonstrou contaminação desse equipamento em 91,9\% dos instrumentos analisados (Olivia-Menacho et al., 2016).

Segundo estudo, 94,4\% dos equipamentos analisados em uma UTI apresentavam contaminação por um ou mais microrganismos, das quais as mais relevantes foram Acinetobacter sp., Staphylococcus aureus, Staphylococcus coagulase negativa (SCN), Staphylococcus saprophyticus, Enterococcus sp., Klebsiella pneumoniae e Streptococcus viridans (Rocha et al., 2015). No presente estudo foi obtido um resultado semelhante, com $93,8 \%$ dos equipamentos analisados contaminados por bactérias.

Há evidências de que os principais microrganismos presentes em superfícies e/ou equipamentos como grades de cama, torneiras, teclados e monitores, podem ser de dois ambientes considerados críticos em unidades hospitalares: unidade terapia intensiva e salas de cirurgia, onde constatou uma similaridade entre bactérias encontradas nesses ambientes e em pacientes, destacando a presença de Staphylococcus sp., Acinetobacter baumannii, Pseudomonas aeruginosa e Klebsiella pneumoniae, resultado semelhante ao encontrado no presente estudo (Dresch et al., 2018).

Os microrganismos possivelmente causadores de IH possuem mecanismos de resistências, sendo necessário um monitoramento direcionado aos aspectos de vigilância como condições ambientais de limpeza e condições sazonais (fenômenos físicos naturais) que podem favorecer a replicação de microrganismos e aumentar a ocorrência de infecções cruzadas (Santos \& Ribeiro, 2016; Oliveira et al., 2017). Do grupo dos microrganismos gram negativos o Acinetobacter baumannii foi o mais frequente nas superfícies e equipamentos analisados, bactéria também encontrada com alta incidência nas hemoculturas de pacientes internados da Sala de Cuidados Intermediários de um Hospital em Petrolina, Pernambuco (Andrade et al., 2021). Esse gênero bacteriano causa grande preocupação no ambiente hospitalar devido a sua capacidade de se adaptar a diferentes habitats e de sua alta capacidade de resistência aos antibióticos. Dentre os mecanismos de resistência deste microrganismo, a produção de carbapenemase do grupo OXA-23 é o mecanismo mais frequente, tornando o A. baumannii resistente aos carbapenêmicos. A elevada taxa de resistência deste microrganismo reflete no aumento da mortalidade em UTI's (Buenahora et al., 2016; Antunes \& Towner, 2014; Nóbrega et al., 2013).

No que diz respeito ao tratamento para infecções pelo A. baumannii, os carbapenêmicos podem ser utilizados, porém o aumento das taxas de resistência a este grupo de antibióticos é uma circunstância que está afetando a escolha. Atualmente, como alternativa aos carbapenêmicos tem-se a polimixina B, a tigeciclina, a ampicilina + sulbactam e a colistina, que em relação a farmacocinética e a farmacodinâmica é a mais estudada (Doi et al., 2015).

O microrganismo gram positivo mais presente no estudo foi o Staphylococcus aureus que é uma das principais causas de infecções humanas em todo o mundo. O marcador de resistência do S. aureus é a oxacilina (MRSA) que representa um problema significativo no ambiente hospitalar. Esta resistência é conferida pela aquisição de um gene que codifica a proteína ligada a penicilina (PBP2a) e o gene mecA é o responsável pela codificação da PBP2a (Peacock \& Peterson, 2015).

No leito 01 foram identificados nas cortinas e no estetoscópio isolados de Enterococcus sp., espécie que está associada a várias infecções humanas e a sua resistência à vancomicina (VRE) está se tornando um grande problema. A resistência do Enterococcus à vancomicina ocorre pela produção de precursores de peptideoglicano na parede celular que se ligam a essa droga. Dentre os genes que conferem resistência à vancomicina, o vanA e vanB são os predominantes, destes os mais encontrados são vanB1, vanB2 e vanB3. Devido a esses genes serem transmitidos via plasmídeo é essencial que as medidas de prevenção sejam tomadas para conter a disseminação de cepas resistentes (Fernandes \& Dhanashree, 2013; Furtado 
et al., 2005; Freitas et al., 2016).

Outro microrganismo presente nas superfícies e equipamentos estudados foi a Klebsiella pneumoniae, que é um bacilo gram negativo presente normalmente na flora intestinal. Esta bactéria pode causar graves infecções como: pneumonias, infecções do trato urinário, infecção de partes moles, infecção do trato gastrointestinal dentre outras. Um dos fatores que tem causado surtos de K. pneumoniae é o surgimento de várias cepas e infecções de $K$. pneumoniae difíceis de tratar que desafiam a comunidade médica (Paczosa \& Mecsas, 2016). Devido aos fatores de virulência e as mudanças e evoluções que ocorrem nas bactérias, a $K$. pneumoniae tem se tornado cada vez mais uma ameaça dentro do ambiente hospitalar. O conhecimento de estratégias e métodos para a identificação da K. pneumoniae Carbapenemase é uma medida importante para conter a sua disseminação (Verdi et al., 2016; Silva et al., 2019).

Medidas como a desinfecção de superfícies juntamente com a lavagem adequada das mãos pelos profissionais atuantes na UTI minimizam a transmissão cruzada de microrganismos possivelmente causadores de IH. O conhecimento de quais microrganismos estão presentes nas superfícies e equipamentos é importantíssimo para adotar estas medidas a fim de promover uma assistência mais adequada para os pacientes críticos assistidos na unidade estudada.

\section{Conclusão}

Assim, o presente estudo mostra que as bactérias como Enterococcus sp., Klebsiella pneumoniae, Acinetobacter baumannii e Staphylococcus aureus, apresentam elevada taxa de resistência aos antibióticos e estão presentes nas superfícies e equipamentos inanimados da UTI, podendo causar possíveis infecções cruzadas. Os profissionais que trabalham no ambiente de terapia intensiva devem estar cientes deste fato e adotar medidas como a desinfecção dos materiais e a higienização correta das mãos antes e após os procedimentos.

Sugere-se ainda, para melhor um melhor conhecimento das IH e seu desenvolvimento, a ampliação deste estudo para a avaliação de outros setores hospitalares; permitindo, dessa forma, uma maior abrangência do conhecimento sobre as contaminações cruzadas nesses ambientes.

\section{Referências}

Andrade, C. W. Q., Silva, K. S. B., Santana, M. M. R., de Oliveira, A. V., Guimarães, M. D., \& Naue, C. R. (2021). Etiologia e resistência de isolados bacterianos de hemoculturas da Sala de Cuidados Intermediários de um Hospital Universitário em Pernambuco. Research, Society and Development, 10(7), e37510716605-e37510716605.

Andrade, D. D., Angerami, E. L., \& Padovani, C. R. (2000). Condição microbiológica dos leitos hospitalares antes e depois de sua limpeza. Revista de saúde pública, 34, 163-169.

Antunes, L., Visca, P., \& Towner, K. J. (2014). Acinetobacter baumannii: evolution of a global pathogen. Pathogens and disease, $71(3), 292-301$.

Boyce, J. M. (2007). Environmental contamination makes an important contribution to hospital infection. Journal of hospital infection, 65, 50-54.

Brixner, B., Renner, J. D. P., \& Krummenauer, E. C. (2016). Contaminação ambiental da UTI pediátrica: fator de risco para a ocorrência de infecções oportunistas. Rev Epidemiol Control Infect, 6(1), 24-8.

Buenahora, R. D. R., Zarate, D. E. B., Sanchez, D. C. C., Sarmiento, D. C. C., \& Gomez, C. C. (2016). Acinetobacter baumannii: patógeno multirresistente emergente. MéD. UIS, 29(2), 113-35.

da Siva, E. L., da Silva, M. S., de Andrade Aoyama, E., \& de Souza, R. A. G. (2019). Klebsiella pneumoniae carbapenamase (kpc): bactéria multirresistente a antibióticos. Revista Brasileira Interdisciplinar de Saúde.

Doi, Y., Murray, G. L., \& Peleg, A. Y. (2015, February). Acinetobacter baumannii: evolution of antimicrobial resistance-treatment options. In Seminars in respiratory and critical care medicine (36, 085-098). Thieme Medical Publishers.

Dresch, F., de Freitas Birkheuer, C., Rempel, C., \& Maciel, M. J. (2018). Contaminação de superfícies localizadas em unidades de terapia intensiva e salas de cirurgia: uma revisão sistemática da literatura. Revista de Epidemiologia e Controle de Infecção, 8(1), 85-91.

Fernandes, S. C., \& Dhanashree, B. (2013). Drug resistance \& virulence determinants in clinical isolatesof Enterococcus species. The Indian journal of medical research, 137(5), 981. 
Research, Society and Development, v. 10, n. 9, e47510918342, 2021

(CC BY 4.0) | ISSN 2525-3409 | DOI: http://dx.doi.org/10.33448/rsd-v10i9.18342

Ferreira, A. M., Andrade, D. D., Almeida, M. T. G. D., Cunha, K. C., \& Rigotti, M. A. (2011). Egg crater mattresses: a deposit of methicillin-resistant staphylococcus aureus? Revista da Escola de Enfermagem da USP, 45, 161-166.

Ferreira, A. M., da Silva Barcelos, L., Rigotti, M. A., de Andrade, D., Andreotti, J. T., \& de Almeida, M. G. (2013). Superfícies do ambiente hospitalar: um possível reservatório de micro-organismos subestimado? revisão integrativa. Revista de Enfermagem UFPE on line, 7(5), 1549-1560.

Freitas, A. R., Tedim, A. P., Francia, M. V., Jensen, L. B., Novais, C., Peixe, L., ... \& Coque, T. M. (2016). Multilevel population genetic analysis of vanA and vanB Enterococcus faecium causing nosocomial outbreaks in 27 countries (1986-2012). Journal of Antimicrobial Chemotherapy, 71(12), 3351-3366.

Furtado, G. H. C., Martins, S. T., Coutinho, A. P., Soares, G. M. M., Wey, S. B., \& Medeiros, E. A. S. (2005). Incidence of vancomycin-resistant Enterococcus at a university hospital in Brazil. Revista de saúde pública, 39, 41-46.

Moraes, C. L., Ribeiro, N. F. G., Costa, D. M., Furlan, V. G., \& Palos, M. A. P. (2013). Vasconcelos LSNOL. Contaminação de equipamentos e superfícies de unidades de terapia intensiva de uma maternidade pública por Staphylococcus coagulase negativa. Rev Patol Trop, 42(4), 387-94.

Nóbrega, M. D. S., Carmo Filho, J. R. D., \& Pereira, M. S. (2013). Evolução da resistência de Pseudomonas aeruginosa e Acinetobacter baumannii em unidades de terapia intensiva.

Oliva-Menacho, J. E., García-Hjarles, M. A., Oliva-Candela, J. A., la Cruz-Roca, D., \& Saturnino, H. (2016). Contaminación con bacterias patógenas de estetoscopios del personal médico en un hospital de nivel III en Lima, Perú. Revista Medica Herediana, 27(2), 83-88.

Oliveira, A. C., de Paula, A. O., Iquiapaza, R., \& Gama, C. S. (2017). Profile of microorganisms associated with colonization and infection in intensive therapy. Revista de Epidemiologia e Controle de Infecção, 7(2), 101-106.

Paczosa, M. K., \& Mecsas, J. (2016). Klebsiella pneumoniae: going on the offense with a strong defense. Microbiology and Molecular Biology Reviews, 80(3), $629-661$.

Peacock, S. J., \& Paterson, G. K. (2015). Mechanisms of methicillin resistance in Staphylococcus aureus. Annual review of biochemistry, 84, $577-601$.

Portaria n 2616 (1998, 12 maio). Estabelece diretrizes e normas para a prevenção e o controle das infecções hospitalares. Diário Oficial da República Federativa do Brasil, Seção 1:89, Brasília-DF.

Rocha, I. V., Ferraz, P. D. M., Farias, T. G. S. D., \& Oliveira, S. R. D. (2015). Resistance of bacteria isolated from equipment in an intensive care unit. Acta Paulista de Enfermagem, 28, 433-439.

Russotto, V., Cortegiani, A., Raineri, S. M., \& Giarratano, A. (2015). Bacterial contamination of inanimate surfaces and equipment in the intensive care unit. Journal of intensive care, 3(1), 1-8.

Sales, V. M., Oliveira, E., Célia, R., Gonçalves, F. R., \& de Melo, C. C. (2014). Análise microbiológica de superfícies inanimadas de uma Unidade de Terapia Intensiva ea segurança do paciente. Revista de Enfermagem Referência, 4(3), 45-53.

Santos, M. C., \& Ribeiro, M. (2016). 4. Bactérias de relevância clínica e seus mecanismos de resistência no contexto das infecções relacionadas à assistência a saúde (IRAS). Revista Científica UMC, 1(1).

Verdi, C. M., Zimmermann, C. E. P., Andrade, E. N. C., Ledur, P. C., \& Velasquez, P. G. (2016). Detecção laboratorial dos mecanismos de resistência da klebsiella pneumoniae: uma revisão. Revista saúde integrada, 9(17), 16-27. 